\title{
Vitamin D and Metabolic Dysfunction-Associated Fatty Liver Disease (MAFLD): An Update
}

\author{
Ilaria Barchetta $\mathbb{D}$, Flavia Agata Cimini and Maria Gisella Cavallo *(D) \\ Department of Experimental Medicine, Sapienza University, Viale Regina Elena 321, 00161 Rome, Italy; \\ ilaria.barchetta@uniroma1.it (I.B.); flaviaagata.cimini@uniroma1.it (F.A.C.) \\ * Correspondence: gisella.cavallo@uniroma1.it; Tel.: +39-(0)6-49974692
}

Received: 14 October 2020; Accepted: 27 October 2020; Published: 28 October 2020

\begin{abstract}
Non-alcoholic fatty liver disease (NAFLD) is the first cause of chronic liver disease worldwide; it ranges from simple steatosis to steatohepatitis (NASH) and, potentially, cirrhosis and hepatocarcinoma. NAFLD is also an independent risk factor for type 2 diabetes, cardiovascular diseases, and mortality. As it is largely associated with insulin resistance and related disorders, NAFLD has been recently re-named as Metabolic dysfunction-Associated Fatty Liver Disease (MAFLD). At present, there are no approved pharmacological treatments for this condition. Vitamin D is a molecule with extensive anti-fibrotic, anti-inflammatory, and insulin-sensitizing properties, which have been proven also in hepatic cells and is involved in immune-metabolic pathways within the gut-adipose tissue-liver axis. Epidemiological data support a relationship hypovitaminosis D and the presence of NAFLD and steatohepatitis (NASH); however, results from vitamin D supplementation trials on liver outcomes are controversial. This narrative review provides an overview of the latest evidence on pathophysiological pathways connecting vitamin D to NAFLD, with emphasis on the effects of vitamin D treatment in MAFLD by a nonsystematic literature review of PubMed published clinical trials. This article conforms to the Scale for Assessment of Narrative Review Articles (SANRA) guidelines. Evidence so far available supports the hypothesis of potential benefits of vitamin D supplementation in selected populations of NAFLD patients, as those with shorter disease duration and mild to moderate liver damage.
\end{abstract}

Keywords: NAFLD; NASH; MAFLD; vitamin D; VDR; adipose tissue; gut; microbiota; inflammation; supplementation

\section{Introduction}

Non-alcoholic fatty liver disease (NAFLD) is the most common chronic liver disease worldwide and its evolution and consequences massively affect health and economic systems of Western countries [1,2]. NAFLD pathogenesis is primarily linked to metabolic impairment and alteration of the glucose-insulin homeostasis. For the tight connection between metabolic diseases and NAFLD, this condition has been recently re-named as Metabolic (dysfunction)-Associated Fatty Liver Disease (MAFLD) [3]; the new acronym MAFLD will be used to replace the term NAFLD throughout this review.

As a vicious circle, once MAFLD is established it increases the hepatic insulin resistance, which, in turn, may trigger, in 30-40\% of cases, MAFLD evolution towards steatohepatitis (NASH), and eventually, cirrhosis, liver failure, and hepatocarcinoma [4,5]. MAFLD also promotes systemic low-grade inflammation and impairs insulin sensitivity in extra-hepatic tissues [6]. Finally, MAFLD increases the risk of type 2 diabetes (T2D) and diabetes' complications and is an established risk factor for cardiovascular morbidity and mortality [7]. Data from four European countries, i.e., France, Germany, Italy, and UK, show that, in 2016, there were about 52 million people with MAFLD, with annual direct medical costs of about $€ 35$ billion, which were highest in patients in working age [8]. Remarkably, 
although MAFLD is already considered as the most rapidly growing contributor to liver mortality and morbidity [9], many reports and real world evidence show that MAFLD is still an under-recognized and under-diagnosed condition in both primary and secondary care [9-11]. These data point towards urgent need of better risk stratification, earlier diagnosis, and management of MAFLD in order to decrease the short- and long-term public health burden of this disease. At present, there are no approved pharmacological treatments for MAFLD or steatohepatitis [9].

Vitamin D is a pleiotropic hormone with functions that extend far beyond the regulation of calcium homeostasis and bone mineralization; in the last decades, experimental evidence has definitively proven the involvement of vitamin D in mediating a number of immune-inflammatory [11] and metabolic [12] processes. Since then, the axis involving the active form of vitamin D-1,25-dihydroxi-vitamin D- and the vitamin D receptor (VDR) has been investigated in relation to disturbances of metabolic pathways in several organs and tissues, primarily in those implicated in metabolic regulation, as the skeletal muscle [13], adipose tissue [14], pancreas [15], and liver [16-18]. The presence of hypovitaminosis D has been associated to the occurrence or development of insulin resistance-related diseases, such as T2D [19], metabolic syndrome [20], and MAFLD [16,18,21-23]. As for vitamin D and liver diseases, in the last years several clinical trials tried to answer the question whether vitamin D supplementation could improve MAFLD, with controversial results.

This review aims to provide an overview of the most recent evidence on pathophysiological pathways connecting the vitamin D/VDR axis to MAFLD development and will focus on new data from clinical trials exploring the safety and efficacy of vitamin D supplementation on liver outcomes in individuals with MAFLD.

This narrative review provides an overview of the latest evidence on pathophysiological pathways connecting vitamin D to NAFLD and describes results from a nonsystematic literature review of published clinical trials on vitamin D treatment in MAFLD. The reporting of this study conforms to the Scale for Assessment of Narrative Review Articles (SANRA) guidelines, a brief critical appraisal for the assessment of nonsystematic articles [24].

A literature search was performed up to October 2020 with database of Pubmed. "Non-alcoholic fatty liver disease" (NAFLD), "non-alcoholic steatohepatitis" (NASH), "fatty liver", "hepatic steatosis", "metabolic-associated fatty liver disease" (MAFLD) were paired with "vitamin D", "cholecalciferol", "calcitriol", " and vitamin D receptor" (VDR) as search terms. Moreover, manual search was also conducted by scrutinizing the reference lists of original articles, meta-analyses, and recent reviews. Inclusion criteria to identify relevant studies were: studies conducted worldwide on adult humans aged $\geq 18$ years with a diagnosis of MAFLD treated with oral or bolus cholecalciferol or calcitriol supplementation in comparison to MAFLD individuals supplemented with placebo. Pilot studies without comparators were also included. Outcome measures were changes of (i) hepatic fat content, as estimated by abdomen ultrasound (US), magnetic resonance imaging (MRI), magnetic resonance spectroscopy (MRS), and liver biopsy; and (ii) hepatic enzymes (aspartate aminotransferase (AST), alanine aminotransferase (ALT), and gamma glutamyl transpeptidase (GGT)), fibrosis markers and scores (cytokeratin-18 (CK-18), procollagen III amino terminal propeptide (PIIINP), Fibrosis-4 Index for Liver Fibrosis (FIB-4), and Enhanced Liver Fibrosis (ELF) score). Study design was randomized clinical trial (RCT) with parallel or cross-over design. Articles published in languages other than English were excluded. For each study, we report surname of first author, published year, region/nation, sample-size and control to intervention ratio, endpoints, types of intervention, doses, and duration of intervention. Data are presented in the manuscript and summarized in a table.

\section{Vitamin D/VDR Axis in the Pathophysiology of MAFLD}

The potential involvement of the vitamin D/VDR axis in the pathogenesis and progression of MAFLD has been suggested by experimental studies linking vitamin D-mediated pathways to key processes leading to liver steatosis, inflammation, and fibrosis. Indeed, vitamin D may influence 
MAFLD development in both direct and indirect manner [25]. Figure 1 summarizes potential pathways linking vitamin D/VDR axis to the development of MAFLD.

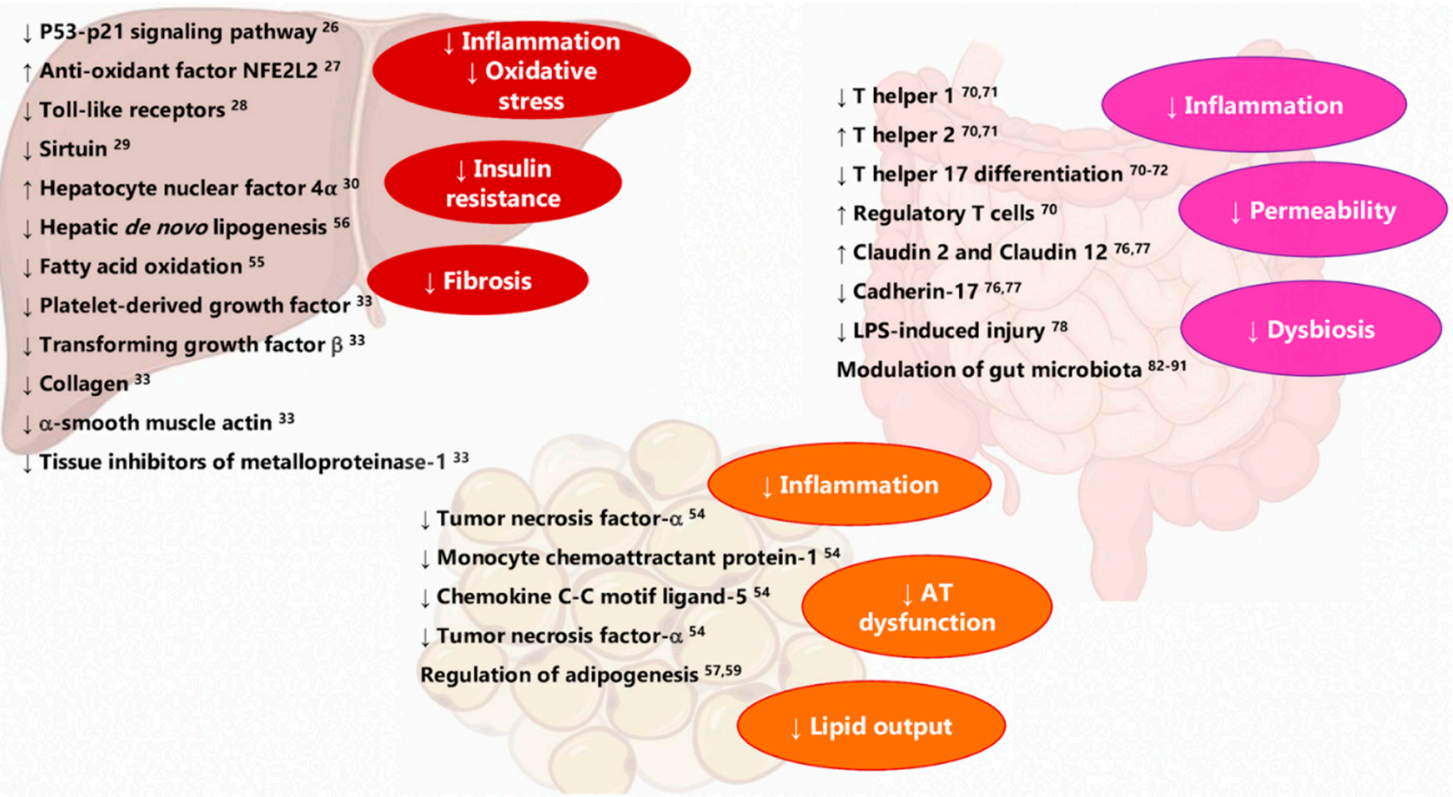

Figure 1. Potential pathways linking vitamin D/vitamin D receptor (VDR) axis to Metabolic dysfunction-Associated Fatty Liver Disease (MAFLD). AT—adipose tissue; $\uparrow$-increase; $\downarrow$-decrease.

Vitamin D and liver homeostasis: Vitamin D displays systemic and tissue-specific anti-inflammatory properties [26] that have been experimentally demonstrated also at the hepatic level. In MAFLD rat models, treatment with active vitamin D reduced liver inflammation and oxidative stress by inhibiting the p53-p21 signaling pathway and associated cell senescence [26]; vitamin D also protected against high fat diet-induced fatty liver by promoting the nuclear translocation of the anti-oxidant molecule nuclear factor erythroid 2-related factor 2 (NFE2L2) [27], decreasing toll-like receptors [28] or repressing sirtuin [29]. Furthermore, in a recent investigation, vitamin D improved hepatic insulin resistance and ameliorated liver steatosis in rodent models via the VDR-mediated activation of the hepatocyte nuclear factor $4 \alpha(\mathrm{HNF} 4 \alpha)$ [30].

On the other side, vitamin D deficiency exacerbates liver inflammation [28]. In humans, hepatic VDR expression inversely correlated with steatosis severity and lobular inflammation at the liver histology [31]. In addition, the activation of VDRs in hepatic macrophages by vitamin D ligands ameliorated liver inflammation, steatosis, and insulin resistance in experimental studies [32].

Vitamin D exerts anti-fibrotic activity in the liver by inhibiting the proliferation of hepatic stellate cells and the expression of pro-fibrotic mediators such as the platelet-derived growth factor (PDGF) and the transforming growth factor $\beta$ (TGF- $\beta$ ); similarly, vitamin D suppresses the expression of collagen, $\alpha$-smooth muscle actin and tissue inhibitors of metalloproteinase-1 [16,33]. Mice knocked-out for the VDR gene spontaneously developed hepatic damage and fibrosis toward to frank cirrhosis [34]. However, active vitamin D administration fails to ameliorate experimentally-induced liver damage in animal models when cirrhosis is already established [35].

Finally, recent clinical evidence pointed towards a role of liver VDR expression in modulating intra-hepatic lipid accumulation, potentially by controlling the local levels of the angiopoietin-like protein 3 and lipoprotein-lipase [36].

In addition to exerting direct insulin-sensitizing, anti-inflammatory, and anti-fibrotic actions in the liver parenchyma, the vitamin D/VDR system participates also to the maintenance of systemic insulin sensitivity and to the homeostasis of organs involved in MAFLD pathogenesis, such as the gut and the adipose tissue [37-41]. 
Vitamin D and insulin sensitivity: The vitamin D/VDR axis regulates metabolic pathways associated with insulin sensitivity and glucose-insulin homeostasis [42-44], favors glucose uptake in muscle cells by upregulating the intracellular expression of the insulin receptor substrate IRS-1 [45] and promotes the expression of the insulin-dependent glucose transporter 4 (GLUT-4) on adipocytes [14]. Moreover, the insulin gene is transcriptionally regulated by VDR in pancreatic $\beta$ cells, and vitamin D deficiency reduces insulin secretory response to carbohydrate loading in experimental models [46]. Indeed, vitamin D insufficiency has been independently associated with insulin resistance in overweight and obese individuals [20], fostering the risk of MAFLD development.

Vitamin D and adipose tissue (AT): Among several pathophysiological processes occurring in presence of chronically excessive caloric intake and weigh gain, the alterations of the AT structure and function represent major determinants of MAFLD development in obesity [37]. In these conditions, AT dysfunction is induced by loss of adipocyte plasticity, insufficient storing capacity, with subsequent matrix rearrangement, hypoxia, and inflammatory reaction [38,39]. In turn, the increased release of fatty acids, pro-inflammatory cytokines, and adipokines [47-50] from stressed adipocytes into the bloodstream leads to low-grade chronic inflammation and abnormal fat deposition in ectopic sites, mostly into the liver [51].

Signatures of AT dysfunction and metabolic impairment are associated to increased intra-hepatic fat accumulation across different body mass index (BMI) classes, in individuals with and without T2D $[38,48,52]$.

In addition to representing the main storage site for vitamin D and expressing key enzymes involved in vitamin D metabolism, AT is also a primary target of vitamin D action, where this hormone modulates insulin-sensitivity, local inflammation, and adipokine secretion. Evidence from clinical [53] and experimental studies [54] showed that treatment with vitamin D improved AT oxidative stress [53] and local concentrations of pro-inflammatory cytokines, such as the tumor necrosis factor $\alpha$ TNF- $\alpha$ and the monocyte chemoattractant protein-1 (MCP-1) [54]. Indeed, vitamin D ameliorates AT inflammation and prevents liver steatosis by reducing both AT output of lipid droplets and hepatic de novo lipogenesis and fatty acid oxidation [55]. Moreover, treatment with calcitriol increases VDR expression in peripheral cells, ameliorates systemic and tissue-associated inflammatory profile, reducing AT inflammation and liver steatosis in animal models [56]. In the AT, the vitamin D/VDR axis influences both adipogenesis and lipid storage into the adipocytes [57]. Of note, AT VDR expression levels are increased in human [58] and experimentally-induced [57] obesity independently from overall vitamin D status. Greater VDR expression may potentially represent a compensatory response to impaired local activation and/or action in condition of altered AT homeostasis. Differential VDR expression in visceral AT may also influence lipid storage and adipocytes enlargement though the transcriptional regulation of angiopoietin-like protein 4 and lipoprotein lipase, which in turn result in liver impairment in obesity [59].

Vitamin D and gut homeostasis: Vitamin D is centrally involved in the regulation of the gut-adipose tissue-liver axis, which represents a major pathway leading to metabolic complications in obesity. In particular, evidence from the last decade underpins a major role of the gut-liver crosstalk in the pathogenesis of MAFLD [37]. Indeed, the gut is nowadays considered as a promising target for experimental therapies of liver steatosis [60,61]. Of note, in humans the gastrointestinal tract is a major site of expression of VDR $[62,63]$ where this receptor mediates the vitamin D action in preserving the gut homeostasis [61] via different regulatory activities such as immuno-modulation [64,65], preservation of the barrier function [66] and regulation of the gut microbiota [67,68].

As an immune adjuvant, vitamin D maintains immune tolerance in the gut microenvironment by suppressing adaptive immunity and up-regulating innate immunity [69]. Indeed, vitamin D inhibits T helper (Th-) 1 and enhances Th2 cell responses; it also decreases Th17 cell differentiation, and increases regulatory $\mathrm{T}$ (TReg) cells $[70,71]$. Th1, Th2, and Th17 cells are known to cause mucosal inflammation and tissue injury, whereas Tregs, which are important intermediaries of immune 
tolerance, play anti-inflammatory functions and mitigate mucosal inflammation and stimulate tissue repair [72-75].

Several studies showed that VDR regulates the expression of the tight junctions zona occludens proteins 1 and 2 (ZO-1 and ZO-2) through the up-regulation of claudin 2 and 12 and the down-regulation of cadherin-17 $[76,77]$ so preserving the adhesive phenotype of intestinal epithelial cells. Moreover, vitamin D repairs tight junctions upon bacterial lipopolysaccharide-mediated injury [78] and maintains mucosal barrier integrity by preventing intestinal cell apoptosis in inflammation $[79,80]$. Mice knocked-out for the intestine VDR gene and those with vitamin D deficiency, displayed alterations of the tight junctions and increased gut permeability [47]. Vitamin D replacement prevents the development of experimentally-induced steatosis, inflammation and fibrosis [81] and restores gut dysbiosis [82].

Indeed, several studies demonstrated that vitamin D/VDR axis is involved in the modulation of gut microbiota [82-91], which in turn impacts on the development of MAFLD in obesity [41]. The genetic ablation of VDR in mice induces gut dysbiosis, reducing Lactobacillus and increasing Clostridium and Bacteroides concentrations [86].

These overall findings warrant further studies evaluating the modulation of vitamin D/VDR signaling as a future therapeutic approach to MAFLD.

\section{Vitamin D Supplementation and MAFLD: Evidence from Clinical Trials}

The observations regarding the link between hypovitaminosis D and the presence of MAFLD suggest that vitamin D supplementation might represent a potential therapeutic option for MAFLD in both children [92,93] and adult populations [18,94,95].

However, data from meta-analyses have not confirmed univocally the presence of a relationship between hypovitaminosis D and MAFLD, especially in trials where histological-, rather than clinical-, or biochemical-outcomes of liver damage were considered [96,97].

Similarly, controversial findings result from interventional clinical trials investigating the efficacy of vitamin D supplementation on parameters of MAFLD and steatohepatitis [98,99] Table 1.

The first pilot study on NASH was conducted by Kitson MT et al. [100] in patients with NASH undergoing liver biopsy before and after six-month 25,000 IU cholecalciferol weekly supplementation and showed no effect on liver outcomes as local inflammation, fibrosis, and intrahepatocyte fat accumulation [100]. Improvement of non-specific clinical and biochemical markers of liver damage after vitamin D supplementation was found in some clinical trials [101-103], whereas no vitamin D effect on the same parameters was shown in other reports [104-106].

In 2016 our group published the results from the first randomized, double-blind, placebo-controlled clinical trial conducted in individuals with T2D and MAFLD, where intrahepatic fat content was measured by magnetic resonance imaging (MRI) [106]. In this study, participants underwent 24-week high-dose oral cholecalciferol supplementation (2000 IU a day) and no effect was shown on either hepatic fat percentage or markers of hepatic injury and/or fibrosis, i.e., serum transaminases, CK-18 and PIIINP levels. Moreover, no beneficial effect was reported for any metabolic parameter, such as body adiposity, glycemic control, estimated insulin resistance, blood pressure or endothelial dysfunction [106].

Conversely, results from a clinical trial conducted by Geier et al. [107] showed that 48-week vitamin D3 treatment (2100 IU vitamin D3 daily) leads to significantly decreased serum ALT and CK-18 levels in twenty individuals with biopsy-proven NASH. Pre- to post-intervention histological changes were investigated in a sub-cohort of seven individuals, finding no significant modification [106].

Dabbaghmanesh et al. [108] published results from a randomized, double blind, placebo controlled trial investigating the effect of three-month high dose oral vitamin D3 (50,000 IU/week) or calcitriol ( $0.25 \mathrm{mg}$ per day) supplementation in over 100 non-diabetic vitamin D deficient individuals with ultrasound-diagnosed NAFLD and normal transaminases. Neither vitamin D3 nor calcitriol supplementation significantly modified liver enzymes in comparison to placebo; no data on liver fat content and/or indirect indexes of hepatic fibrosis were available in this study [108]. 
Table 1. Characteristics of clinical trials evaluating vitamin D supplementation on MAFLD. Abbreviations: US-Ultrasound, MRI-Magnetic Resonance Imaging, ELF-Enhanced Liver Fibrosis score, IU—International Units.

\begin{tabular}{|c|c|c|c|c|c|c|c|c|}
\hline \multirow{2}{*}{$\begin{array}{c}\text { Author } \\
\text { Foroughi M. [104] }\end{array}$} & \multirow{2}{*}{$\begin{array}{l}\text { Year } \\
2014\end{array}$} & \multirow{2}{*}{$\begin{array}{c}\text { Country } \\
\text { Iran }\end{array}$} & \multirow{2}{*}{$\begin{array}{c}\begin{array}{c}\text { No. } \\
\text { (Control/Intervention) } \\
\text { Endpoint }\end{array} \\
60(30 / 30) \\
\end{array}$} & \multirow{2}{*}{$\begin{array}{c}\text { Duration } \\
\begin{array}{c}\text { Hepatic steatosis (US), } \\
\text { enzymes }\end{array}\end{array}$} & \multirow{2}{*}{$\begin{array}{c}\begin{array}{c}\text { Dose of } \\
\text { Vitamin D }\end{array} \\
10 \text { weeks }\end{array}$} & \multicolumn{2}{|c|}{ Type of Intervention } & \multirow{2}{*}{$\begin{array}{c}\text { Results } \\
\text { No effect }\end{array}$} \\
\hline & & & & & & $50,000 \mathrm{IU}$ per week & Vitamin D3 & \\
\hline Sharifi N. [105] & 2014 & India & $53(26 / 27)$ & Hepatic enzymes & 4 months & $50,000 \mathrm{IU}$ per 14 days & Vitamin D3 & No effect \\
\hline Kitson M.T. [100] & 2016 & Australia & 12 & Liver histology & 24 weeks & $25,000 \mathrm{IU}$ per week & Vitamin D3 & No effect \\
\hline Lorvand Amiri H. [102] & 2016 & Iran & $120(36 / 74)$ & Hepatic enzymes & 12 weeks & 1000 IU day & Calcitriol & Significant effect \\
\hline Lorvand Amiri H. [103] & 2016 & Iran & $73(36 / 37)$ & Hepatic steatosis (US) & 12 weeks & 1000 IU day & Calcitriol & Significant effect \\
\hline Barchetta I. [106] & 2016 & Italy & $55(29 / 26)$ & Intrahepatic fat content (MRI) & 24 weeks & 2000 IU day & Vitamin D3 & No effect \\
\hline Sakpal M. [101] & 2017 & Iran & $81(30 / 51)$ & Hepatic enzymes & 6 months & 600,000 IU i.m./6 months & Vitamin D3 & Significant effect \\
\hline Geier A. [107] & 2018 & Switzerland & $18(10 / 8)$ & Liver histology & 48 weeks & 2100 IU day & Vitamin D3 & No effect \\
\hline $\begin{array}{l}\text { Dabbaghmanesh } \\
\text { M.H. [108] }\end{array}$ & 2018 & Iran & $63(32 / 31)$ & Hepatic enzymes & 12 weeks & $50,000 \mathrm{IU}$ per week & Vitamin D3 & No effect \\
\hline Naderpoor N. [109] & 2018 & Australia & $54(28 / 26)$ & Hepatic enzymes & 16 weeks & 4000 IU day & Vitamin D3 & No effect \\
\hline Javed Z. [110] & 2019 & UK & $37(18 / 19)$ & Hepatic enzymes, ELF score & 3 months & 3200 IU day & Vitamin D3 & Significant effect \\
\hline
\end{tabular}


A similar investigation was conducted by Naderpoor et al. [109] aiming to explore the effects of vitamin D supplementation (100,000 loading dose of cholecalciferol followed by 4000 IU daily for 16 weeks) on liver enzymes in 54 overweight/obese individuals with vitamin D deficiency at the time of the study enrolment and no history of liver disease, without finding any change [109].

A recent randomized, double-blind, placebo-controlled trial explored the effect of vitamin D supplementation (3200 IU daily for three months) on cardiovascular risk factors, hormones, and liver markers in women with polycystic ovary syndrome, finding modest improvement of ALT and enhanced liver fibrosis (ELF) score, along with a trend towards reduced insulin-resistance-estimated by the Homeostatic Model Assessment for Insulin Resistance (HOMA-IR) index-in the actively treated group versus placebo [110].

Overall, clinical trials conducted so far have adopted non-homogenous inclusion criteria, recruited population with broad range of MAFLD severity and selected non-comparable outcome measures; this inhomogeneity has inevitably led to conflicting results.

\section{Potential Pitfalls and Future Directions}

Vitamin D and VDR regulate numerous mechanisms associated with inflammatory responses, insulin function and overall immune-metabolism. Accumulating data from mechanistic studies confirm a major involvement of vitamin $\mathrm{D}$ in both liver homeostasis itself and in the gut-adipose tissue-liver axis, and many observational studies have reported the existence of a close relationship between hypovitaminosis D and MAFLD. However, some other investigations have not found any correlation between vitamin $\mathrm{D}$ status and liver damage at the histological examination.

In the last years, several clinical trials have tested potential benefits of vitamin D on MAFLD in in cohorts of individuals with different extension of liver damage, comorbidities and comedications, producing inconsistent findings. The latest meta-analysis which has explored the effects of vitamin D supplementation on cardio-metabolic and hepatic outcomes in patients with MAFLD, including data from almost 550 participants [99], concluded that vitamin D supplementation may have beneficial effects on glucose-insulin metabolism, ALT, and triglycerides in the youngest sub-group of patients ( $<45$ years old) [99]. Moreover, based on the clinical trials published so far, longer exposure to vitamin D dose less than $3500 \mathrm{IU}$ per day, seems to exert the best effect on transaminases reduction in MAFLD patients [99].

In the light of the available evidence, a major role behind successful vitamin D supplementation on liver parameters is played by the improvement of blood glucose and insulin levels [100-112]. Indeed, in individuals without established diabetes and antidiabetic therapies, vitamin D may positively impact on glucose tolerance and insulin resistance and reduce directly and indirectly liver impairment in MAFLD. Conversely, once diabetes is established, vitamin D may not be sufficient to remodulate glucose homeostasis and/or its potential effects may be hidden by concomitant therapies. Indeed, in dysmetabolic individuals undertaking multiple treatments, as those with frank metabolic syndrome and diabetes, a certain effect of comedications on liver status, as intended as either damage-in addition to MAFLD itself, or potential benefit as for some new antidiabetic agents [113], cannot be definitively ruled out.

Differently from what reported in terms of potential benefit of vitamin D supplementation on glucose-insulin profile, evidence of efficacy on liver fibrosis and inflammation is still lacking.

These overall findings may support the hypothesis that vitamin D supplementation may exert beneficial effects mostly in younger individuals, with shorter disease duration and mild to moderate liver damage [114] and/or in addition to anti-fibrotic agents [115].

\section{Conclusions}

Convincing experimental data show that the vitamin D/VDR axis is directly involved in the modulation of metabolic and inflammatory pathways associated with the development of MAFLD in overweight and obesity. Indeed, vitamin D and VDR take part not only in intra-hepatic regulation of 
insulin sensitivity, fat accumulation, and immune-inflammatory responses, but also in the homeostasis of organs that are primarily involved in the pathogenesis of NAFLD and NASH, such as gut and adipose tissue.

Clinical trials do not report unequivocal beneficial effects of vitamin D supplementation on markers of liver impairment in individuals with MAFLD. Moreover, the investigations conducted so far involved small populations and were markedly heterogeneous in terms of inclusion criteria, study design and outcome measures.

Nonetheless, the evidence available shows positive effects of long-term low-dose vitamin D treatment in the youngest populations of MAFLD subjects, without hepatic fibrotic damage and clinically overt complications and comorbidities, such as T2D. Vitamin D is a molecule with beneficial effects on a large number of organs and systems, primarily the skeleton and immune system [11-13], and its supplementation is considered a highly cost-effective strategy for disease prevention, i.e., fractures' risk reduction [116].

Further studies on larger populations of individuals, selected in relation to criteria emerging from available clinical trials, may be needed before drawing general conclusions on the benefit of vitamin D supplementation in patients with fatty liver disease.

Author Contributions: I.B. and F.A.C. conducted the literature research, I.B. drafted the manuscript, M.G.C. revised the paper. All authors have read and agreed to the published version of the manuscript.

Funding: I.B. is supported by a grant from "Fondazione Eli Lilly Italia".

Conflicts of Interest: The authors declare no conflict of interest.

\section{References}

1. Younossi, Z.M.; Koenig, A.B.; Abdelatif, D.; Fazel, Y.; Henry, L.; Wymer, M. Global epidemiology of nonalcoholic fatty liver disease-Meta-analytic assessment of prevalence, incidence, and outcomes. Hepatology 2016, 64, 73-84. [CrossRef] [PubMed]

2. Eslam, M.; Newsome, P.N.; Sarin, S.K.; Anstee, Q.M.; Targher, G.; Romero-Gomez, M.; Zelber-Sagi, S.; Wong, V.W.-S.; Dufour, J.-F.; Schattenberg, J.M.; et al. A new definition for metabolic dysfunction-associated fatty liver disease: An international expert consensus statement. J. Hepatol. 2020, 73, 202-209. [CrossRef] [PubMed]

3. European Association for the Study of the Liver (EASL); European Association for the Study of Diabetes (EASD); European Association for the Study of Obesity (EASO). EASL-EASD-EASO clinical practice guidelines for the management of non-alcoholic fatty liver disease. J. Hepatol. 2016, 64, 1388-1402. [CrossRef] [PubMed]

4. Ekstedt, M.; Franzén, L.E.; Mathiesen, U.L.; Thorelius, L.; Holmqvist, M.; Bodemar, G.; Kechagias, S. Long-term follow-up of patients with NAFLD and elevated liver enzymes. Hepatology 2006, 44, 865-873. [CrossRef] [PubMed]

5. Samuel, V.T.; Shulman, G.I. Nonalcoholic Fatty Liver Disease as a Nexus of Metabolic and Hepatic Diseases. Cell Metab. 2018, 27, 22-41. [CrossRef]

6. Targher, G.; Day, C.P.; Bonora, E. Risk of cardiovascular disease in patients with nonalcoholic fatty liver disease. N. Engl. J. Med. 2010, 363, 1341-1350. [CrossRef] [PubMed]

7. Targher, G.; Byrne, C.D.; Tilg, H. NAFLD and increased risk of cardiovascular disease: Clinical associations, pathophysiological mechanisms and pharmacological implications. Gut 2020, 69, 1691-1705. [CrossRef]

8. Paik, J.M.; Golabi, P.; Younossi, Y.; Mishra, A.; Younossi, Z.M. Changes in the Global Burden of Chronic Liver Diseases From 2012 to 2017: The Growing Impact of Nonalcoholic Fatty Liver Disease. Hepatology 2020. [CrossRef]

9. Alexander, M.; Loomis, A.K.; Fairburn-Beech, J.; Van Der Lei, J.; Duarte-Salles, T.; Prieto-Alhambra, D.; Ansell, D.; Pasqua, A.; Lapi, F.; Rijnbeek, P.; et al. Real-world data reveal a diagnostic gap in non-alcoholic fatty liver disease. BMC Med. 2018, 16, 130. [CrossRef]

10. Marcellin, P.; Kutala, B.K. Liver diseases: A major, neglected global public health problem requiring urgent actions and large-scale screening. Liver Int. 2018, 38 (Suppl. 1), 2-6. [CrossRef] 
11. Charoenngam, N.; Holick, M.F. Immunologic Effects of Vitamin D on Human Health and Disease. Nutrients 2020, 12, 2097. [CrossRef] [PubMed]

12. Szymczak-Pajor, I.; Drzewoski, J.; Śliwińska, A. The Molecular Mechanisms by Which Vitamin D Prevents Insulin Resistance and Associated Disorders. Int. J. Mol. Sci. 2020, 21, 6644. [CrossRef] [PubMed]

13. Benetti, E.; Mastrocola, R.; Chiazza, F.; Nigro, D.; D'Antona, G.; Bordano, V.; Fantozzi, R.; Aragno, M.; Collino, M.; Minetto, M.A. Effects of vitamin D on insulin resistance and myosteatosis in diet-induced obese mice. PLoS ONE 2018, 13, e0189707. [CrossRef] [PubMed]

14. Pittas, A.G.; Joseph, N.A.; Greenberg, A.S. Adipocytokines and insulin resistance. J. Clin. Endocrinol. Metab. 2004, 89, 447-452. [CrossRef] [PubMed]

15. Riachy, R.; Vandewalle, B.; Conte, J.K.; Moerman, E.; Sacchetti, P.; Lukowiak, B.; Gmyr, V.; Bouckenooghe, T.; Dubois, M.; Pattou, F. 1,25-dihydroxyvitamin D3 protects RINm5F and human islet cells against cytokine-induced apoptosis: Implication of the antiapoptotic protein A20. Endocrinology 2002, 143, 4809-4819. [CrossRef]

16. Barchetta, I.; Cimini, F.A.; Cavallo, M.G. Vitamin D Supplementation and Non-Alcoholic Fatty Liver Disease: Present and Future. Nutrients 2017, 9, 1015. [CrossRef]

17. Abramovitch, S.; Dahan-Bachar, L.; Sharvit, E.; Weisman, Y.; Ben Tov, A.; Brazowski, E.; Reif, S. Vitamin D inhibits proliferation and profibrotic marker expression in hepatic stellate cells and decreases thioacetamide-induced liver fibrosis in rats. Gut 2011, 60, 1728-1737. [CrossRef]

18. Barchetta, I.; Angelico, F.; Del Ben, M.; Baroni, M.G.; Pozzilli, P.; Morini, S.; Cavallo, M.G. Strong association between non alcoholic fatty liver disease (NAFLD) and low 25(OH) vitamin D levels in an adult population with normal serum liver enzymes. BMC Med. 2011, 9, 85. [CrossRef]

19. Dawson-Hughes, B.; Staten, M.A.; Knowler, W.C.; Nelson, J.; Vickery, E.M.; Leblanc, E.S.; Neff, L.M.; Park, J.; Pittas, A.G. D2d Research Group Investigators. Intratrial Exposure to Vitamin D and New-Onset Diabetes among Adults with Prediabetes: A Secondary Analysis from the Vitamin D and Type 2 Diabetes (D2d) Study. Diabetes Care 2020, dc201765. [CrossRef]

20. Barchetta, I.; De Bernardinis, M.; Capoccia, D.; Baroni, M.G.; Fontana, M.; Fraioli, A.; Morini, S.; Leonetti, F.; Cavallo, M.G. Hypovitaminosis D is independently associated with metabolic syndrome in obese patients. PLoS ONE 2013, 8, e68689. [CrossRef]

21. Barchetta, I. Could vitamin d supplementation benefit patients with chronic liver disease? Gastroenterol. Hepatol. 2012, 8, 755-757.

22. Cimini, F.A.; Barchetta, I.; Carotti, S.; Bertoccini, L.; Baroni, M.G.; Vespasiani-Gentilucci, U.; Cavallo, M.G.; Morini, S. Relationship between adipose tissue dysfunction, vitamin D deficiency and the pathogenesis of non-alcoholic fatty liver disease. World J. Gastroenterol. 2017, 23, 3407-3417. [CrossRef] [PubMed]

23. Cimini, F.A.; Barchetta, I.; Carotti, S.; Morini, S.; Cavallo, M.G. Overview of studies of the vitamin D/vitamin D receptor system in the development of non-alcoholic fatty liver disease. World J. Gastrointest. Pathophysiol. 2019, 10, 11-16. [CrossRef] [PubMed]

24. Baethge, C.; Goldbeck-Wood, S.; Mertens, S. SANRA-a scale for the quality assessment of narrative review articles. Res. Integr. Peer Rev. 2019, 4, 5. [CrossRef] [PubMed]

25. Eliades, M.; Spyrou, E. Vitamin D: A new player in non-alcoholic fatty liver disease? World J. Gastroenterol. 2015, 21, 1718-1727. [CrossRef] [PubMed]

26. Ma, M.; Long, Q.; Chen, F.; Zhang, T.; Wang, W. Active vitamin D impedes the progression of non-alcoholic fatty liver disease by inhibiting cell senescence in a rat model. Clin. Res. Hepatol. Gastroenterol. 2020, 44, 513-523. [CrossRef] [PubMed]

27. Zhu, C.G.; Liu, Y.X.; Wang, H.; Wang, B.P.; Qu, H.Q.; Wang, B.L.; Zhu, M. Active form of vitamin D ameliorates non-alcoholic fatty liver disease by alleviating oxidative stress in a high-fat diet rat model. Endocr. J. 2017, 64, 663-673. [CrossRef]

28. Roth, C.L.; Elfers, C.T.; Figlewicz, D.P.; Melhorn, S.J.; Morton, G.J.; Hoofnagle, A.; Yeh, M.M.; Nelson, J.E.; Kowdley, V.K. Vitamin D deficiency in obese rats exacerbates nonalcoholic fatty liver disease and increases hepatic resistin and Toll-like receptor activation. Hepatology 2012, 55, 1103-1111. [CrossRef]

29. Wu, T.; Liu, Y.H.; Fu, Y.C.; Liu, X.M.; Zhou, X.H. Direct evidence of sirtuin downregulation in the liver of non-alcoholic fatty liver disease patients. Ann. Clin. Lab. Sci. 2014, 44, 410-418. 
30. Zhang, H.; Shen, Z.; Lin, Y.; Zhang, J.; Zhang, Y.; Liu, P.; Zeng, H.; Yu, M.; Chen, X.; Ning, L.; et al. Vitamin D receptor targets hepatocyte nuclear factor $4 \alpha$ and mediates protective effects of vitamin $\mathrm{D}$ in nonalcoholic fatty liver disease. J. Biol. Chem. 2020, 295, 3891-3905. [CrossRef]

31. Barchetta, I.; Carotti, S.; Labbadia, G.; Vespasiani-Gentilucci, U.; Muda, A.O.; Angelico, F.; Silecchia, G.; Leonetti, F.; Fraioli, A.; Picardi, A.; et al. Liver vitamin D receptor, CYP2R1, and CYP27A1 expression: Relationship with liver histology and vitamin D3 levels in patients with nonalcoholic steatohepatitis or hepatitis C virus. Hepatology 2012, 56, 2180-2187. [CrossRef] [PubMed]

32. Dong, B.; Zhou, Y.; Wang, W.; Scott, J.; Kim, K.H.; Sun, Z.; Guo, Q.; Lu, Y.; Gonzales, N.M.; Wu, H.; et al. Vitamin D Receptor Activation in Liver Macrophages Ameliorates Hepatic Inflammation, Steatosis, and Insulin Resistance in Mice. Hepatology 2020, 71, 1559-1574. [CrossRef]

33. Beilfuss, A.; Sowa, J.P.; Sydor, S.; Beste, M.; Bechmann, L.P.; Schlattjan, M.; Syn, W.-K.; Wedemeyer, I.; Mathé, Z.; Jochum, C.; et al. Vitamin D counteracts fibrogenic TGF-beta signaling in human hepatic stellate cells both receptor-dependently and independently. Gut 2015, 64, 791-799. [CrossRef] [PubMed]

34. Ding, N.; Yu, R.T.; Subramaniam, N.; Sherman, M.H.; Wilson, C.; Rao, R.; Leblanc, M.; Coulter, S.; He, M.; Scott, C.; et al. A vitamin D receptor/SMAD genomic circuit gates hepatic fibrotic response. Cell 2013, 153, 601-613. [CrossRef]

35. Abramovitch, S.; Sharvit, E.; Weisman, Y.; Bentov, A.; Brazowski, E.; Cohen, G.; Volovelsky, O.; Reif, S. Vitamin D inhibits development of liver fibrosis in an animal model but cannot ameliorate established cirrhosis. Am. J. Physiol. Gastrointest. Liver Physiol. 2015, 308, G112-G120. [CrossRef]

36. Barchetta, I.; Cimini, F.A.; Chiappetta, C.; Bertoccini, L.; Ceccarelli, V.; Capoccia, D.; Gaggini, M.; Di Cristofano, C.; Della Rocca, C.; Silecchia, G.; et al. Relationship between hepatic and systemic angiopoietin-like 3, hepatic Vitamin D receptor expression and NAFLD in obesity. Liver Int. 2020, 40, 2139-2147. [CrossRef] [PubMed]

37. Tilg, H.; Adolph, T.E.; Moschen, A.R. Multiple Parallel Hits Hypothesis in NAFLD—Revisited After a Decade. Hepatology 2020. [CrossRef]

38. Cimini, F.A.; Barchetta, I.; Ciccarelli, G.; Leonetti, F.; Silecchia, G.; Chiappetta, C.; Di Cristofano, C.; Capoccia, D.; Bertoccini, L.; Ceccarelli, V.; et al. Adipose tissue remodelling in obese subjects is a determinant of presence and severity of fatty liver disease. Diabetes Metab. Res. Rev. 2020, e3358. [CrossRef]

39. Du Plessis, J.; Van Pelt, J.; Korf, H.; Mathieu, C.; Van Der Schueren, B.; Lannoo, M.; Oyen, T.; Topal, B.; Fetter, G.; Nayler, S.; et al. Association of Adipose Tissue Inflammation With Histologic Severity of Nonalcoholic Fatty Liver Disease. Gastroenterology 2015, 149, 635-648.e614. [CrossRef]

40. Barchetta, I.; Cimini, F.A.; Leonetti, F.; Guida, A.; Di Cristofano, C.; Silecchia, G.; Orho-Melander, M.; Melander, O.; Cavallo, M.G. Increased Plasma Proneurotensin Levels Identify NAFLD in Adults With and Without Type 2 Diabetes. J. Clin. Endocrinol. Metab. 2018, 103, 2253-2260. [CrossRef]

41. Longo, L.; Ferrari, J.T.; Rampelotto, P.H.; Dellavia, G.H.; Pasqualotto, A.; Oliveira, C.P.; Cerski, C.T.S.; Da Silveira, T.R.; Uribe-Cruz, C.; Alvares-Da-Silva, M.R. Gut Dysbiosis and Increased Intestinal Permeability Drive microRNAs, NLRP-3 Inflammasome and Liver Fibrosis in a Nutritional Model of Non-Alcoholic Steatohepatitis in Adult Male Sprague Dawley Rats. Clin. Exp. Gastroenterol. 2020, 13, 351-368. [CrossRef] [PubMed]

42. Zhou, Q.G.; Hou, F.F.; Guo, Z.J.; Liang, M.; Wang, G.B.; Zhang, X. 1,25-Dihydroxyvitamin D improved the free fatty-acid-induced insulin resistance in cultured C2C12 cells. Diabetes Metab. Res. Rev. 2004, 24, 459-464. [CrossRef] [PubMed]

43. Parker, L.; Levinger, I.; Mousa, A.; Howlett, K.; de Courten, B. Plasma 25-Hydroxyvitamin D Is Related to Protein Signaling Involved in Glucose Homeostasis in a Tissue-Specific Manner. Nutrients 2016, 8, 631. [CrossRef] [PubMed]

44. Elseweidy, M.M.; Amin, R.S.; Atteia, H.H.; Ali, M.A. Vitamin D3 intake as regulator of insulin degrading enzyme and insulin receptor phosphorylation in diabetic rats. Biomed. Pharmacother. 2017, 85, 155-159. [CrossRef]

45. Alkharfy, K.M.; Al-Daghri, N.M.; Yakout, S.M.; Hussain, T.; Mohammed, A.K.; Krishnaswamy, S. Influence of vitamin D treatment on transcriptional regulation of insulin-sensitive genes. Metab. Syndr. Relat. Disord. 2013, 11, 283-288. [CrossRef] 
46. Bornstedt, M.E.; Gjerlaugsen, N.; Pepaj, M.; Bredahl, M.K.L.; Thorsby, P.M. Vitamin D Increases Glucose Stimulated Insulin Secretion from Insulin Producing Beta Cells (INS1E). Int. J. Endocrinol. Metab. 2019, 17, e74255. [CrossRef]

47. Barchetta, I.; Cimini, F.A.; Ciccarelli, G.; Baroni, M.G.; Cavallo, M.G. Sick fat: The good and the bad of old and new circulating markers of adipose tissue inflammation. J. Endocrinol. Investig. 2019, 42, 1257-1272. [CrossRef]

48. Barchetta, I.; Angelico, F.; Del Ben, M.; Di Martino, M.; Cimini, F.A.; Bertoccini, L.; Polimeni, L.; Catalano, C.; Fraioli, A.; Del Vescovo, R.; et al. Phenotypical heterogeneity linked to adipose tissue dysfunction in patients with Type 2 diabetes. Clin. Sci. 2016, 130, 1753-1762. [CrossRef]

49. Barchetta, I.; Cimini, F.A.; Capoccia, D.; De Gioannis, R.; Porzia, A.; Mainiero, F.; Di Martino, M.; Bertoccini, L.; De Bernardinis, M.; Leonetti, F.; et al. WISP1 Is a Marker of Systemic and Adipose Tissue Inflammation in Dysmetabolic Subjects With or Without Type 2 Diabetes. J. Endocr. Soc. 2017, 1, 660-670. [CrossRef]

50. Cimini, F.A.; Barchetta, I.; Porzia, A.; Mainiero, F.; Costantino, C.; Bertoccini, L.; Ceccarelli, V.; Morini, S.; Baroni, M.G.; Lenzi, A.; et al. Circulating IL-8 levels are increased in patients with type 2 diabetes and associated with worse inflammatory and cardiometabolic profile. Acta Diabetol. 2017, 54, 961-967. [CrossRef]

51. Rosso, C.; Kazankov, K.; Younes, R.; Esmaili, S.; Marietti, M.; Sacco, M.; Carli, F.; Gaggini, M.; Salomone, F.; Møller, H.J.; et al. Crosstalk between adipose tissue insulin resistance and liver macrophages in non-alcoholic fatty liver disease. J. Hepatol. 2019, 71, 1012-1021. [CrossRef]

52. Gastaldelli, A.; Cusi, K. From NASH to diabetes and from diabetes to NASH: Mechanisms and treatment options. JHEP Rep. 2019, 1, 312-328. [CrossRef] [PubMed]

53. Ionica, M.; Aburel, O.M.; Văduva, A.O.; Petrus, A.; Rațiu, S.; Olariu, S.; Sturza, A.; Muntean, M.-D. Vitamin $\mathrm{D}$ alleviates oxidative stress in adipose tissue and mesenteric vessels from obese patients with subclinical inflammation. Can. J. Physiol. Pharmacol. 2020, 98, 85-92. [CrossRef] [PubMed]

54. Farhangi, M.A.; Mesgari-Abbasi, M.; Hajiluian, G.; Nameni, G.; Shahabi, P. Adipose Tissue Inflammation and Oxidative Stress: The Ameliorative Effects of Vitamin D. Inflammation 2017, 40, 1688-1697. [CrossRef] [PubMed]

55. Marziou, A.; Philouze, C.; Couturier, C.; Astier, J.; Obert, P.; Landrier, J.-F.; Riva, C. Vitamin D Supplementation Improves Adipose Tissue Inflammation and Reduces Hepatic Steatosis in Obese C57BL/6J Mice. Nutrients 2020, 12, 342. [CrossRef]

56. Su, Y.-B.; Li, T.-H.; Huang, C.-C.; Tsai, H.-C.; Huang, S.; Hsieh, Y.-C.; Yang, Y.-Y.; Huang, Y.-H.; Hou, M.-C.; Lin, H.-C. Chronic calcitriol supplementation improves the inflammatory profiles of circulating monocytes and the associated intestinal/adipose tissue alteration in a diet-induced steatohepatitis rat model. PLoS ONE 2018, 13, e0194867. [CrossRef]

57. Xu, Y.; Lou, Y.; Kong, J. VDR regulates energy metabolism by modulating remodeling in adipose tissue. Eur. J. Pharmacol. 2019, 865, 172761. [CrossRef]

58. Jonas, M.; Kurylowicz, A.; Bartoszewicz, Z.; Lisik, W.; Jonas, M.; Koźniewski, K.; Puzianowska-Kuznicka, M. Vitamin D Receptor Gene Expression in Adipose Tissue of Obese Individuals is Regulated by miRNA and Correlates with the Pro-Inflammatory Cytokine Level. Int. J. Mol. Sci. 2019, 20, 5272. [CrossRef]

59. Barchetta, I.; Chiappetta, C.; Ceccarelli, V.; Cimini, F.A.; Bertoccini, L.; Gaggini, M.; Di Cristofano, C.; Silecchia, G.; Lenzi, A.; Leonetti, F.; et al. Angiopoietin-Like Protein 4 Overexpression in Visceral Adipose Tissue from Obese Subjects with Impaired Glucose Metabolism and Relationship with Lipoprotein Lipase. Int. J. Mol. Sci. 2020, 21, E7197. [CrossRef]

60. Aron-Wisnewsky, J.; Warmbrunn, M.; Nieuwdorp, M.; Clement, K. Nonalcoholic Fatty Liver Disease: Modulating Gut Microbiota to Improve Severity? Gastroenterology 2020, 158, 1881-1898. [CrossRef]

61. Porras, D.; Nistal, E.; Martínez-Flórez, S.; González-Gallego, J.; García-Mediavilla, M.V.; Sánchez-Campos, S. Intestinal Microbiota Modulation in Obesity-Related Non-alcoholic Fatty Liver Disease. Front. Physiol. 2018, 9, 1813. [PubMed]

62. Fakhoury, H.M.; Kvietys, P.R.; AlKattan, W.; Al Anouti, F.; Elahi, M.A.; Karras, S.N.; Grant, W.B. Vitamin D and intestinal homeostasis: Barrier, microbiota, and immune modulation. J. Steroid. Biochem. Mol. Biol. 2020, 200, 105663. [PubMed]

63. Wang, Y.; Zhu, J.; DeLuca, H.F. Where is the vitamin D receptor? Arch. Biochem. Biophys. 2012, 523, $123-133$.

64. Dimitrov, V.; White, J.H. Vitamin D signaling in intestinal innate immunity and homeostasis. Mol. Cell. Endocrinol. 2017, 453, 68-78. [PubMed] 
65. Fakhoury, H.M.; Kvietys, P.R.; AlKattan, W.; Al Anouti, F.; Elahi, M.A.; Karras, S.N.; Grant, W.B. Vitamin D signaling maintains intestinal innate immunity and gut microbiota: Potential intervention for metabolic syndrome and NAFLD. Am. J. Physiol. Gastrointest. Liver Physiol. 2020, 318, G542-G553.

66. O'Sullivan, M. Does Vitamin D Protect the Gut Mucosal Barrier? Mechanistic Insights from Experimental Colitis. Dig. Dis. Sci. 2015, 60, 1871-1872.

67. Sun, J. Dietary vitamin D, vitamin D receptor, and microbiome. Curr. Opin. Clin. Nutr. Metab. Care. 2018, 21, 471-474.

68. Malaguarnera, L. Vitamin D and microbiota: Two sides of the same coin in the immunomodulatory aspects. Int. Immunopharmacol. 2020, 79, 106112.

69. Chang, S.H.; Chung, Y.; Dong, C. Vitamin D suppresses Th17 cytokine production by inducing C/EBP homologous protein [CHOP) expression. J. Biol. Chem. 2010, 285, 38751-38755.

70. Sun, F.; Luo, J.C.; Xing, F.; Zhang, J.Z.; Xu, Z.H. 1,25(OH) (2) D(3) inhibited Th17 cells differentiation via regulating the NF- $\mathrm{KB}$ activity and expression of IL-17. Cell Prolif. 2018, 51, e12461.

71. Sun, M.; He, C.; Cong, Y.; Liu, Z. Regulatory immune cells in regulation of intestinal inflammatory response to microbiota. Mucosal. Immunol. 2015, 8, 969-978. [CrossRef]

72. Rossi, M.; Bot, A. The Th17 cell population and the immune homeostasis of the gastrointestinal tract. Int. Rev. Immunol. 2013, 32, 471-474. [CrossRef] [PubMed]

73. Pandiyan, P.; Bhaskaran, N.; Zou, M.; Schneider, E.; Jayaraman, S.; Huehn, J. Microbiome dependent regulation of T(regs) and Th17 cells in mucosa. Front. Immunol. 2019, 10, 426. [PubMed]

74. Mao, K.; Baptista, A.P.; Tamoutounour, S.; Zhuang, L.; Bouladoux, N.; Martins, A.J.; Huang, Y.; Gerner, M.Y.; Belkaid, Y.; Germain, R.N. Innate and adaptive lymphocytes sequentially shape the gut microbiota and lipid metabolism. Nature 2018, 554, 255-259. [CrossRef] [PubMed]

75. Wang, L.; Zhu, L.; Qin, S. Gut Microbiota Modulation on Intestinal Mucosal Adaptive Immunity. J. Immunol. Res. 2019, 2019, 4735040. [CrossRef]

76. Kong, J.; Zhang, Z.; Musch, M.W.; Ning, G.; Sun, J.; Hart, J.; Bissonnette, M.; Li, Y.C. Novel role of the vitamin D receptor in maintaining the integrity of the intestinal mucosal barrier. Am. J. Physiol. Gastrointest. Liver Physiol. 2008, 294, G208-G216. [CrossRef]

77. Chen, S.-W.; Ma, Y.-Y.; Zhu, J.; Zuo, S.; Zhang, J.-L.; Chen, Z.-Y.; Chen, G.; Wang, X.; Pan, Y.-S.; Liu, Y.-C.; et al. Protective effect of 1,25-dihydroxyvitamin D3 on ethanol-induced intestinal barrier injury both in vitro and in vivo. Toxicol. Lett. 2015, 237, 79-88. [CrossRef]

78. Chen, S.-W.; Wang, P.-Y.; Zhu, J.; Chen, G.; Zhang, J.-L.; Chen, Z.-Y.; Zuo, S.; Liu, Y.-C.; Pan, Y.-S. Protective effect of 1,25-dihydroxyvitamin $\mathrm{d} 3$ on lipopolysaccharide-induced intestinal epithelial tight junction injury in caco-2 cell monolayers. Inflammation 2015, 38, 375-383. [CrossRef]

79. Chen, S.; Zhu, J.; Chen, G.; Zuo, S.; Zhang, J.; Chen, Z.; Wang, X.; Li, J.; Liu, Y.; Wang, P. 1,25-Dihydroxyvitamin D3 preserves intestinal epithelial barrier function from TNF- $\alpha$ induced injury via suppression of NF-kB p65 mediated MLCK-P-MLC signalling pathway. Biochem. Biophys. Res. Commun. 2015, 460, 873-878. [CrossRef]

80. He, L.; Liu, T.; Shi, Y.; Tian, F.; Hu, H.; Deb, D.K.; Chen, Y.; Bissonnette, M.; Li, Y.C. Gut Epithelial Vitamin D Receptor Regulates Microbiota-Dependent Mucosal Inflammation by Suppressing Intestinal Epithelial Cell Apoptosis. Endocrinology 2018, 159, 967-979. [CrossRef]

81. Su, D.; Nie, Y.; Zhu, A.; Chen, Z.; Wu, P.; Zhang, L.; Luo, M.; Sun, Q.; Cai, L.; Lai, Y.; et al. Vitamin D Signaling through Induction of Paneth Cell Defensins Maintains Gut Microbiota and Improves Metabolic Disorders and Hepatic Steatosis in Animal Models. Front. Physiol. 2016, 7, 498. [CrossRef] [PubMed]

82. Mu, Y.; Li, J.; Kang, J.-H.; Eto, H.; Zai, K.; Kishimura, A.; Hyodo, F.; Mori, T.; Katayama, Y. A Lipid-Based Nanocarrier Containing Active Vitamin D3 Ameliorates NASH in Mice via Direct and Intestine-Mediated Effects on Liver Inflammation. Biol. Pharm. Bull. 2020, 43, 1413-1420. [PubMed]

83. Ryz, N.R.; Patterson, S.J.; Zhang, Y.; Ma, C.; Huang, T.; Bhinder, G.; Wu, X.; Chan, J.; Glesby, A.; Sham, H.P.; et al. Active vitamin D (1,25-dihydroxyvitamin D3) increases host susceptibility to Citrobacter rodentium by suppressing mucosal Th17 responses. Am. J. Physiol. Gastrointest. Liver Physiol. 2012, 303, G1299-G1311. [PubMed]

84. Assa, A.; Vong, L.; Pinnell, L.J.; Rautava, J.; Avitzur, N.; Johnson-Henry, K.C.; Sherman, P.M. Vitamin D deficiency predisposes to adherent-invasive Escherichia coli-induced barrier dysfunction and experimental colonic injury. Inflamm. Bowel. Dis. 2015, 21, 297-306. [CrossRef] 
85. Lagishetty, V.; Misharin, A.V.; Liu, N.Q.; Lisse, T.S.; Chun, R.F.; Ouyang, Y.; McLachlan, S.M.; Adams, J.S.; Hewison, M. Vitamin D deficiency in mice impairs colonic antibacterial activity and predisposes to colitis. Endocrinology 2010, 151, 2423-2432.

86. Jin, D.; Wu, S.; Zhang, Y.G.; Lu, R.; Xia, Y.; Dong, H.; Sun, J. Lack of vitamin D receptor causes dysbiosis and changes the functions of the murine intestinal microbiota. Clin. Ther. 2015, 37, 996-1009.

87. Chen, J.; Waddell, A.; Lin, Y.D.; Cantorna, M.T. Dysbiosis caused by vitamin D receptor deficiency confers colonization resistance to Citrobacter rodentium through modulation of innate lymphoid cells. Mucosal. Immunol. 2015, 8, 618-626. [CrossRef]

88. Wu, S.; Liao, A.P.; Xia, Y.; Li, Y.C.; Li, J.-D.; Sartor, R.B.; Sun, J. Vitamin D receptor negatively regulates bacterial-stimulated NF-kappa B activity in intestine. Am. J. Pathol. 2010, 177, 686-697.

89. Kim, J.-H.; Yamaori, S.; Tanabe, T.; Johnson, C.H.; Krausz, K.W.; Kato, S.; Gonzalez, F.J. Implication of intestinal VDR deficiency in inflammatory bowel disease. Biochim. Biophys. Acta 2013, 1830, 2118-2128. [CrossRef]

90. Wu, S.; Yoon, S.; Zhang, Y.-G.; Lu, R.; Xia, Y.; Wan, J.; Petrof, E.O.; Claud, E.C.; Chen, D.; Sun, J. Vitamin D receptor pathway is required for probiotic protection in colitis. Am. J. Physiol. Gastrointest. Liver Physiol. 2015, 309, G341-G349. [CrossRef]

91. Wang, J.; Thingholm, L.B.; Skiecevičienė, J.; Rausch, P.; Kummen, M.; Hov, J.R.; Degenhardt, F.; Heinsen, F.-A.; Rühlemann, M.C.; Szymczak, S.; et al. Genome-wide association analysis identifies variation in vitamin D receptor and other host factors influencing the gut microbiota. Nat. Genet. 2016, 48, 1396-1406. [CrossRef] [PubMed]

92. Manco, M.; Ciampalini, P.; Nobili, V. Low levels of 25-hydroxyvitamin D (3) in children with biopsy-proven nonalcoholic fatty liver disease. Hepatology 2010, 51, 2229. [CrossRef]

93. Nobili, V.; Giorgio, V.; Liccardo, D.; Bedogni, G.; Morino, G.; Alisi, A.; Cianfarani, S. Vitamin D levels and liver histological alterations in children with nonalcoholic fatty liver disease. Eur. J. Endocrinol. 2014, 170, 547-553. [CrossRef]

94. Targher, G.; Bertolini, L.; Scala, L.; Cigolini, M.; Zenari, L.; Falezza, G.; Arcaro, G. Associations between serum 25-hydroxyvitamin D3 concentrations and liver histology in patients with non-alcoholic fatty liver disease. Nutr. Metab. Cardiovasc. Dis. 2007, 17, 517-524. [CrossRef] [PubMed]

95. Keane, J.T.; Elangovan, H.; Stokes, R.A.; Gunton, J.E. Vitamin D and the liver-correlation or cause? Nutrients 2018, 10, 496. [CrossRef] [PubMed]

96. Saberi, B.; Dadabhai, A.S.; Nanavati, J.; Wang, L.; Shinohara, R.T.; Mullin, G.E. Vitamin D levels do not predict the stage of hepatic fibrosis in patients with non-alcoholic fatty liver disease: A PRISMA compliant systematic review and meta-analysis of pooled data. World J. Hepatol. 2018, 10, 142-154. [CrossRef] [PubMed]

97. Jaruvongvanich, V.; Ahuja, W.; Sanguankeo, A.; Wijarnpreecha, K.; Upala, S. Vitamin D and histologic severity of nonalcoholic fatty liver disease: A systematic review and meta-analysis. Dig. Liver Dis. 2017, 49, 618-622. [CrossRef]

98. Tabrizi, R.; Moosazadeh, M.; Lankarani, K.B.; Akbari, M.; Heydari, S.T.; Kolahdooz, F.; Samimi, M.; Asemi, Z. The effects of vitamin D supplementation on metabolic profiles and liver function in patients with non-alcoholic fatty liver disease: A systematic review and meta-analysis of randomized controlled trials. Diabetes Metab Syndr. 2017, 11 (Suppl. 2), S975-S982. [CrossRef]

99. Guo, X.F.; Wang, C.; Yang, T.; Li, S.; Li, K.L.; Li, D. Vitamin D and non-alcoholic fatty liver disease: A meta-analysis of randomized controlled trials. Food Funct. 2020, 11, 7389-7399. [CrossRef]

100. Kitson, M.T.; Pham, A.; Gordon, A.; Kemp, W.; Roberts, S.K. High-dose vitamin D supplementation and liver histology in NASH. Gut 2016, 65, 717-718. [CrossRef]

101. Sakpal, M.; Satsangi, S.; Mehta, M.; Duseja, A.; Bhadada, S.; Das, A.; Dhiman, R.K.; Chawla, Y.K. Vitamin D supplementation in patients with nonalcoholic fatty liver disease: A randomized controlled trial. JGH Open 2017, 1, 62-67. [CrossRef] [PubMed]

102. Amiri, H.L.; Agah, S.; Tolouei Azar, J.; Hosseini, S.; Shidfar, F.; Mousavi, S.N. Effect of daily calcitriol supplementation with and without calcium on disease regression in non-alcoholic fatty liver patients following an energy-restricted diet: Randomized, controlled, double-blind trial. Clin. Nutr. 2017, 36, 1490-1497. [CrossRef] [PubMed] 
103. Amiri, H.L.; Agah, S.; Mousavi, S.N.; Hosseini, A.F.; Shidfar, F. Regression of Non-Alcoholic Fatty Liver by Vitamin D Supplement: A Double-Blind Randomized Controlled Clinical Trial. Arch. Iran. Med. 2016, 19, 631-638.

104. Foroughi, M.; Maghsoudi, Z.; Ghiasvand, R.; Iraj, B.; Askari, G. Effect of Vitamin D Supplementation on C-reactive Protein in Patients with Nonalcoholic Fatty Liver. Int. J. Prev. Med. 2014, 5, 969-975.

105. Sharifi, N.; Amani, R.; Hajiani, E.; Cheraghian, B. Does vitamin D improve liver enzymes, oxidative stress, and inflammatory biomarkers in adults with non-alcoholic fatty liver disease? A randomized clinical trial. Endocrine 2014, 47, 70-80. [CrossRef]

106. Barchetta, I.; Del Ben, M.; Angelico, F.; Di Martino, M.; Fraioli, A.; La Torre, G.; Saulle, R.; Perri, L.; Morini, S.; Tiberti, C.; et al. No effects of oral vitamin D supplementation on non-alcoholic fatty liver disease in patients with type 2 diabetes: A randomized, double-blind, placebo-controlled trial. BMC Med. 2016, 14, 92. [CrossRef]

107. Geier, A.; Eichinger, M.; Stirnimann, G.; Semela, D.; Tay, F.; Seifert, B.; Tschopp, O.; Bantel, H.; Jahn, D.; Maggio, E.M.; et al. Treatment of non-alcoholic steatohepatitis patients with vitamin D: A double-blinded, randomized, placebo-controlled pilot study. Scand. J. Gastroenterol. 2018, 53, 1114-1120. [CrossRef]

108. Dabbaghmanesh, M.H.; Danafar, F.; Eshraghian, A.; Omrani, G.R. Vitamin D supplementation for the treatment of non-alcoholic fatty liver disease: A randomized double blind placebo controlled trial. Diabetes Metab. Syndr. 2018, 12, 513-517. [CrossRef]

109. Naderpoora, N.; Mousa, A.; de Courtenc, M.; Scraggd, R.; de Courtena, B. The relationship between 25-hydroxyvitamin D concentration and liver enzymes in overweight or obese adults: Cross-sectional and interventional outcomes. J. Steroid. Biochem. Mol. Biol. 2018, 177, 193-199. [CrossRef]

110. Javed, Z.; Papageorgiou, M.; Deshmukh, H.; Kilpatrick, E.S.; Mann, V.; Corless, L.; Abouda, G.; Rigby, A.S.; Atkin, S.L.; Sathyapalan, T. A Randomized, Controlled Trial of Vitamin D Supplementation on Cardiovascular Risk Factors, Hormones, and Liver Markers in Women with Polycystic Ovary Syndrome. Nutrients 2019, 11, 188. [CrossRef]

111. George, P.S.; Pearson, E.R.; Witham, M.D. Effect of vitamin D supplementation on glycaemic control and insulin resistance: A systematic review and meta-analysis. Diabet. Med. 2012, 29, e142-e150. [CrossRef] [PubMed]

112. Poolsup, N.; Suksomboon, N.; Plordplong, N. Effect of vitamin D supplementation on insulin resistance and glycaemic control in prediabetes: A systematic review and meta-analysis. Diabet. Med. 2016, 33, 290-299. [CrossRef] [PubMed]

113. Budd, J.; Cusi, K. Role of Agents for the Treatment of Diabetes in the Management of Nonalcoholic Fatty Liver Disease. Curr. Diabetes Rep. 2020, 20, 59. [CrossRef] [PubMed]

114. Della Corte, C.; Carpino, G.; De Vito, R.; De Stefanis, C.; Alisi, A.; Cianfarani, S.; Overi, D.; Mosca, A.; Stronati, L.; Cucchiara, S.; et al. Docosahexanoic Acid Plus Vitamin D Treatment Improves Features of NAFLD in Children with Serum Vitamin D Deficiency: Results from a Single Centre Trial. PLoS ONE 2016, 11, e0168216. [CrossRef]

115. Moore, M.P.; Cunningham, R.P.; Dashek, R.J.; Mucinski, J.M.; Rector, R.S. A Fad too Far? Dietary Strategies for the Prevention and Treatment of NAFLD. Obesity 2020, 28, 1843-1852. [CrossRef]

116. Weaver, C.M.; Bischoff-Ferrari, H.A.; Shanahan, C.J. Cost-benefit analysis of calcium and vitamin D supplements. Arch. Osteoporos. 2019, 14, 50. [CrossRef]

Publisher's Note: MDPI stays neutral with regard to jurisdictional claims in published maps and institutional affiliations.

(C) 2020 by the authors. Licensee MDPI, Basel, Switzerland. This article is an open access article distributed under the terms and conditions of the Creative Commons Attribution (CC BY) license (http://creativecommons.org/licenses/by/4.0/). 